\title{
Bakım Paketi Nedir?
}

\author{
What is A Care Bundle?
}

\author{
Yazile SAYIN $^{1}$
}

İletişim/Correspondence: Yazile SAYIN Adres/Adress: Bezmialem Vakıf Üniversitesi, Sağlık Bilimleri Fakültesi, Hemşirelik Bölümü, Merkez Mahallesi Silahtarağa Caddesi No:189 Eyüp İstanbul/ TURKEY Tel: 02124012600 Faks: 02124531883 E-mail: yaziles@gmail.com

\begin{abstract}
$\ddot{O} Z$
Bakım paketi, bakım göstergelerinin net açıklandı̆̆ bir araçtır. Genellikle üç ya da beş kanıt temelli bir grup girişimi içerir. "Institute for Healthcare Improvement (Sağlık Bakımını Iyileştirme Enstitüsü)" tarafindan, riskli tedavi uygulanan hastalara mümkün olan en iyi bakımın güvenli bir şekilde verilmesini sağlamak amacıyla geliştirilmiştir. Çoğunlukla yoğun bakım üniteleri tarafindan kullanılmaktadır.Bakım paketindeki girişimler hasta bakımındaki belli durum ve olaylarla ilgilidir. Paketinin içerdiği tüm girişimler zorunlu ve yeterlidir. Paketin gücü arkasında bilim ve tutarlı bir yöntem olmasından gelmektedir. Genellikle kontrol listesine benzetilmekte ise de ondan farklı ve eşsiz öğeler içermektedir: öğe sayısı, öğelerin kanıt düzeyi (düzey I veya II), sorumluluk düzeyi (belirli bir kişi ya da ekibe sahiptir) gibi. Bakım paketinin uygulanmasında karşılaşılan üç sorun vardır: Paketin bütün olarak yapılmaması, geliştirilmiş bir bakım paketine girişim eklenmesi, her şeyin paket olarak adlandırılması. Beklenen sonuçlar için, bakım paketinin bütün olarak yapılması önemlidir.
\end{abstract}

Anahtar Kelimeler: Bakım paketi, kanıta dayalı uygulama, yoğun bakım.

\section{ABSTRACT}

The care bundle is an explicit tool with clear parameters. A care bundle usually consists of a group of between three and five evidence-based interventions. Institute for Healthcare Improvement developed the concept of "bundles" to help health care providers more reliably deliver the best possible care for patients undergoing treatments with risks. It is mostly used by intensive care units. Interventions of care bundle are related to a particular condition or event in patient care. Interventions of care bundle are all necessary and all sufficient. The power of the care bundle comes from the body of science behind it and the method of implementation: with complete consistency. The changes in the care bundle are all necessary and all sufficient. It resembles a checklist, but a bundle is more than that. The care bundle has specific elements that make it unique: such as number of items, the level of evidence items (level I or II), liability levels (an identified person or team owns it). There are three problems seen on the use of care bundle: don't complete the care bundle as a whole, attempt addition to an enhanced care bundle, tendency to want to call everything a bundle. Finally, it is important that the care bundle is done as a whole for the expected outcomes. Keywords: Care bundle, evidence-based practice, critical care.

\section{GİRIŞ}

Bakım paketleri hastane infeksiyonlarının tıbbi hatalar olduğuna ilişkin görüşlerin önem kazanmasıyla ileri sürülen çeşitli çözüm yollarının en önemlilerinden biridir (Berenholtz, Dorman, Ngo ve Provonost 2002; IHI 2012). Etkili olabilmesi için doğru anlaşılması ve kullanılması son derece önemli uygulamalardan biridir. Ne yazık ki günümüzde bakım paketi ile ilgili yanlış algılar onun doğru kullanılmasını sınırlamakta ve başarısını düşürmektedir (Haraden 2015; Horner ve Bellamy 2012; McCarron 2011). Bu makalenin amacı, literatür bilgileri doğrultusunda bakım paketinin karakteristik özelliklerini ve bakım paketi ile ilgili en sık karşılaşılan sorunları tartışarak bakım paketlerinin etkin kullanılmasına 1şık tutmaktır.

9. Ulusal Türk Cerrahi ve Ameliyathane Hemşireliği Kongresi'nde panel olarak sunulmuştur (12-15 Kasım 2015, Sarıgerme- Muğla/ TÜRKiYE), 'Doç. Dr. Bezmialem Vakıf Üniversitesi, Sağllk Bilimleri Fakültesi, Hemşirelik Bölümü, İstanbul/ TURKEY

Yazının gönderilme tarihi: 02.03.2016

Yazının basım için kabul tarihi: 03.04.2017

doi: $10.17672 /$ fnhd.74202 
Tarihçeye bakıldığında, 1990'lı yılların sonlarında ve bu yüzyılın ilk yarısında, paket girişiminden yoğun bakımlar için söz edildiği rapor edilmektedir. Bu girişimde şiddetli sepsis ve septik şok tedavisinde hedefe yönelik bir dizi protokol uygulanmış ve çok ilgi çekici sonuçlara ulaşıldığ 1 bildirilmiştir. Yayınlanan bu sonuçlar, tartışmalı da olsa, zamanın en ilgi çekici çalışması olarak kabul edilmiştir. Ayrıca, çalışmanın bir bakım paketi olarak kabul edilebilir protokol elementleri içerdiği duyurulmuştur (Horner ve Bellamy 2012). İlerleyen yıllarda Berenholtz, Dorman, Ngo ve Provonost (2002) tarafindan 2002'de "ventilatör bakım paketi” tanımlanmıştır. Bu paket günümüzde ilk geliştirilen bakım paketi olarak kabul edilmekte ve orijinal değeri bulunmaktadır (Tablo 1). Paketteki girişimlerin mortalite ve mobidite üzerinde etkili olduğu gösterilmiştir.

Tablo 1. Ventilatör Bakım Paketi Bileşenleri

\begin{tabular}{|ll|}
\hline 1. & Derin ven trombozu profilaksisi \\
\hline 2. & Gastrik ülser profilaksisi \\
\hline 3. & Yatak başının $30-45$ derece yükseltilmesi \\
\hline 4. & Günlük sedasyon işlemine ara verilmesi \\
\hline
\end{tabular}

Kaynak: Berenholtz, S., Dorman, T., Ngo, K., Provonost, P. J. (2002). Qualitative review of intensive care quality indicators. J Crit Care, 17(1): 1-12.

Paketler, Amerika Birleşik Devletlerinde "Institute for Healthcare Improvement” (Sağlık Bakımını İyileştirme Enstitüsü) tarafından, hasta güvenliğini sağlamak ve bakım kalitesini artırmak amaciyla 2004 yılında “100.000 yaşayan programı" ve 2006 yılında "5 milyon yaşayan" kampanyasının bir parçası olarak ilgi görmüştür. Bu kampanyalarda çeşitli klinik durumlarda bakım kalitesini ve hasta güvenliğini artırmak amaçlanmıştı. Kampanyalar yoğun bakım alanındaki sepsis, kardiyak ve solunum yetmezliği olan hastaları kapsıyordu. Bu kampanyalar aracılı̆g ile şiddetli sepsis olaylarında 2009 yılına kadar sağ kalımın \%25 arttırılması hedeflenmişti. Bu yıllarda, uluslararası arenada paketler tanınmaya başlamış ve güçlü bir şekilde ilerleme göstermişti. Bu ilerlemede anahtar rolün "yaşayan sepsis kampanyası"na ait olduğu bildirilmiştir.
O dönemde, bir dizi protokol içeren (kabul edilebilen en iyi girişimlerden hazırlanmış) bakım paketlerinin bu başarısı büyük bir ilgi ile karşılanmıştı (Horner ve Bellamy 2012).

Berenholtz ve ark. (2002, 2004)'nın çalışmalarının yarattı̆g1 etki nedeniyle 2000'li yıllarda bakım paketi, bakımın kalitesini değerlendirme aracı olarak da tanımlanmıştır. Bakımla ilgili işlevleri iyileştirmek için bir yöntem olarak görülebileceği bildirilmiştir. $\mathrm{Bu}$ yaklaşımda bakım paketinin iki ana unsuruna işaret edilmiştir. Biri girişimin kendisi, diğeri bakım sürecinin yapılmas1/ gerçekleştirilmesidir (denetim) (Horner ve Bellamy 2012).

Günümüzde bakım paketi, kanıta dayalı bakım protokolü olarak da tanımlanmaktadır. Ancak, her bakım protokolünün bakım paketi olamayacağı bildirilmektedir. Paket, belli bir hastalık belirtisi, bakımı ya da tedavisi için gruplandırılmış, kanıt düzeyi yüksek ve sınırlı sayıdaki bakım girişimlerinden oluşmaktadır (Fulbrook ve Mooney 2003).

Bakım paketi ile çalışmanın birçok yararı olduğu belirtilmektedir (Aboelela, Stone ve Larson 2007; McCarron 2011; IHI 2012; Marwick ve Davey 2009).

Bunlar;

- Klinikte dikkatsizliği azaltması,

- Komplikasyonları azaltması,

- Hastanede/yoğun bakımda kalış süresini kısaltması,

- Morbiditeyi azaltmas1,

- Klinikte bakımın denetimini geliştirmesi,

- Maliyeti azaltmasi ve

- Kaynakların etkin kullanımını sağlaması olarak gösterilmektedir.

Günümüzde geliştirilmiş birçok bakım paketi vardır: Ventilatör bakım paketi, santral kateter bakım paketi, şiddetli sepsis bakım paketi, metisiline dirençli Staphylococcus aureus bakım paketi, inme ve geçici iskemik atak bakım paketi gibi (Berenholtz ve ark. 2004; Cooke ve Holmes 2007; Fong ve ark. 2007; McCarron 2011; Smith 2007). Çalışmalarda paket uygulamasının çoğunlukla yoğun bakım hastalarında kullanıldığ gösterilmiştir. Bununla birlikte, paketin farklı bakım 
gerektiren durumlarda da (basınç yarası bakım paketi, ölmekte olan hasta bakım paketi gibi) kullanıldığına ve bazı özellikleri olduğuna işaret edilmiştir (Clark, Curry ve Byfieldt 2015; Coyer ve ark. 2015).

\section{Bakım Paketinin Özelliği}

Hasta bakımında istenen sonuçlara ulaşmak için paket adı altında birçok bakım girişimi uygulanmaktadır. Ancak, bunların hepsini paket olarak nitelendirmenin doğru olmadığı bildirilmektedir (Horner ve Bellamy 2012; McCarron 2011). Bakım paketleri ile ilgili bildirilen bazı özellikler:

- Bakım paketi uygulaması her ne kadar yeni bir uygulama olsa da, kanıt temelli bakım girişimlerini içermesi en güçlü özelliğidir. Arkasında bilimin olması ve uygulama yönteminin süreklilik gerektirmesi ona ulusal ve uluslararası standartlar kazandırmaktadır (Berenholtz ve ark. 2002; Haraden 2015; Horner ve Bellamy 2012; McCarron 2011).

- Paketin içinde bakımla ilgili öğe (bakım girişimi) sayısının genellikle 3 ile 5 arasında olması önerilmektedir. Her bir girişimin kendi alanında kabul edilen en iyi girişim (hasta için en etkili bakım) olması gerektiği bildirilmektedir. Bu girişimlerin randomize kontrollü deneysel çalışma sonuçlarından elde edilmiş kanıtlara (tercihen düzey I ve düzey II) dayandırılması önerilmektedir (Horner ve Bellamy 2012).

- Bakım paketinde, en iyi kanıtlara göre bakımın nasıl verileceği gösterilmekte, ne olması gerektiği tartışılmamaktadır. Bu nedenle, hemşire ve hekimlerin paketin buradaki amacını anlamasının pakete uyum için önemli olduğu vurgulanmaktadır (Fulbrook ve Mooney 2003; Horner ve Bellamy 2012; McCarron 2011).

- Bakım paketini oluşturan öğelerin her biri yükssek düzeyli kanıtlardan oluştuğu için paket kesin, açık ve basit olarak tanımlanmaktadır. Paket girişimleri için "Evet" ya da "Hayır" cevabı vardır. "Evet, girişimin yapıldığını, "Hayır” yapılmadığını göstermektedir (McCarron 2011).

- Paketi oluşturan tüm girişimlerin yapılması durumunda paket tamamlanmış olarak kabul edilmek- tedir. Paketteki her bir girişimin paketin bütününe hizmet ettiği varsayılmaktadır. Klinik olarak, hasta adına pozitif bir karar almayı gerektirecek bir durum doğmadıç̧a, her bir girişim her hasta için \%100 aynı şekilde uygulanmalıdır. Bu da bakım paketinin bir bütün olarak tamamlanmasının beklenen sonuçlar açısından önemine işaret etmektedir (Fulbrook ve Mooney 2003; Haraden 2015; Horner ve Bellamy 2012; McCarron 2011). Bununla birlikte bazı lokal farklı1ıkların, paketin bütününün uygulanmasını engelleyebileceği bildirilmektedir. Örneğin: ventilatör bakım paketinin 30-45 derece baş pozisyonuna spinal bir yaralanma durumunda bir sinırlama gelmesi gibi (Horner ve Bellamy 2012).

- Bakım paketi girişimlerinin zamanında ve yerinde yapılmasının önemli olduğu vurgulanmaktadır. Örneğin, hastanın yatağında, her gün sabah saatlerinde gibi (ya da belli bir saatte) (Haraden 2015; McCarron 2011).

- Bütünü kapsadığı için paket yaklaşımının hem kanıta dayalı uygulamayı hem de sürecin konularını denetleme ve ölçmede kullanılabileceği bildirilmektedir. Bu durum onların statik bir bakım sürecini göstermediklerine, yeni kanıtlar doğdukça güncellenmeleri gerektiğine işaret etmektedir (Horner ve Bellamy 2012).

Bütün bu ayırt edici özelliklerine karşın bakım paketleri en çok kontrol listesi (checklist) ile karıştırılmaktadir (Haraden 2015).

\section{Bakım paketi ve kontrol listesi arasındaki farklar}

Kontrol listeleri güvenli bir bakımı sağlamak açısından önemli araçlar olarak tanımlanmaktadır. Bakım paketi ile arasında belirgin farklar olduğuna dikkat çekilmektedir (Haraden 2015; McCarron 2011). Bunlar:

- Kontrol listesi, yapılması yararlı olan uygulamaların ya da süreçlerin (önemli ve işe yarar, fakat kanıt temelli olmayan değişiklikler), paket ise yapılması zorunlu süreçlerin (randomize kontrollü deneyler tarafından kanıtlanmış) karışımıdır (Haraden 2015). 
- Kontrol listesindeki bazı girişimlerinin yapılması hasta için iyi olmasına karşın, zorunlu değildir ve yapılmadıklarında hasta zarar görmemektedir. Paketteki girişimlerin ise hastanın iyiliği için zorunlu girişimleri kapsadığından dolayı, bunlardan birinin yap1lmamas1 durumunda hasta ciddi komplikasyonlarla karşı karşıya kalmaktadır. Örneğin, bir bakım paketinde dört girişim varsa ve onlardan herhangi biri kaldırılır ya da değiştirilir ise beklenen sonuçlara ulaşılamaz. Böyle bir durumda hastanın iyileşmesi için önceki kadar şansı yoktur. Çünkü, bu girişimler birbirine bağlıdır ve başarıya ulaşmak için her birinin mutlaka tamamlanması gerekmektedir. Oysa kontrol listesinde, bazı girişimler bakım verici tarafindan gerekli görülmediğinde atlanabilmekte veya zamanı değiştirilebilmektedir (Borgert, Goossens ve Dongelmans 2015; Haraden 2015; McCarron 2011).

- Bakım paketinde, kontrol listesinde her zaman olmayan bir sorumluluk düzeyi vardır. Paketin uygulanması, sorumlu belirli bir kişi (doktor ya da hemşire) ya da ekip gerektirmektedir. Kontrol listesi ise herkes tarafindan uygulanabilmektedir. Uygulanması bir kişi ya da ekibin sorumluluğu altında değildir (Haraden 2015).

- Kontrol listesinin içerdiği konular her zaman bitirilmeyebilir. Örneğin, bir kontrol listesinde eczacı bir şey yaparken, hemşire başka bir şey, hekim de ayrı bir şey yapabilir. Günün sonunda ise bu liste üzerindeki iş artık belli bir sağlık çalışanının / ekibinin işi değildir. Paket girişimleri bir kimsenin "Sen şuna bak, ben de buna bakarım" diyebileceği bir şey değildir. Kimin neyi, ne zaman yapacağ1 belirlenmiştir ve çok nettir/ kesindir (Haraden 2015).

- Kontrol listesi pakete göre daha fazla madde içermektedir.

Kontrol listesi asla bir bakım paketi yerine geçmemesine karşın, birlikte kullanılabilecekleri rapor edilmektedir. Bununla birlikte bakım paketlerinin olduğu yerde, kontrol listelerinin kullanımının tartışmalı olduğu bildirilmektedir. Çünkü, kanıt temelli girişimlerin yerine getirilmesi beklenen sonuçları sağlayacağı düşünülmektedir (Borgert ve ark. 2015; Haraden 2015; Malouf-Todaro, Barker, Jupiter, Tipton ve Peace 2013; McCarron 2011). Yine de, kontrol listelerinin bakım paketlerine uyumu artırdığı, birlikte kullanılmalarının önemli bir fark oluşturmasa da yararlı olduğu gösterilmiştir (Malouf-Todaro ve ark. 2013).

Kontrol listelerinin özellikle tıbbi hataları azaltmada önemli katkılar sağladığı bildirilmiştir. Bakım paketinin etkinliğini artırmadaki katkıları tartışmalı da olsa güvenli bir hizmetin sağlanmasında ve bakım kalitesinin geliştirilmesinde kullanılmaları önerilmektedir (Lashoher ve Pronovost 2010; Malouf-Todaro ve ark. 2013; Vijayasekar ve Steele 2009).

\section{Bakım Paketi ile İlgili Sorunlar}

Genel olarak üç sorundan söz edilmektedir. Bunlardan biri, paket girişimlerinin bütün olarak uygulanmamasıdır. Bu en sık karşılaşılan sorun olarak gösterilmektedir (Haraden 2015; Horner ve Bellamy 2012). Oysa paket uygulaması arada kalınmış bir duruma izin vermemektedir. Nedeninin ise genellikle bu konudaki bilgi yetersizliği olduğu bildirilmektedir (Borgert ve ark. 2015; Hamishehkar ve ark. 2014).

Paketteki girişimlerden birinin bir kez bile yapılmamasının ya da ertelenmesinin paketin bütününe zarar verdiğine dikkat çekilmektedir. Paket girişimlerinin bütün olarak yapılmasını engelleyen bir durum varsa bunun nedeninin açık bir şekilde kaydedilmesi önerilmektedir. Çünkü, beklenen sonuçlara ulaşılmayı engelleyen durumların bilinmesi, kanıta dayalı uygulamaların doğru değerlendirilmesi açısından önemlidir (Horner ve Bellamy 2012).

İkinci karşılaşılan sorun, sağlık ekibi üyelerinin, geliştirilmiş bir bakım paketine girişim ekleme eğilimidir. $\mathrm{Bu}$ durumda bakım paketinin kapsamı genişlemekte, artık üzerinde çalışılamayacak ya da takip edilmesi imkansız ve etkili olmayan bir duruma gelmektedir. Çünkü bir bakım paketinin kapsamı genişledikçe anlamı zayıflamaktadır. Bakım paketlerine eklenmeye çalışılan girişimlere bakıldığında, çoğunun bakımın 
vazgeçilmez öğeleri olduğu görülmektedir. Örneğin, "el yıkama" (özel bir yıkama tekniği içermiyorsa) gibi bir girişimi bakım paketine eklemeye gerek yoktur. Çünkü, hiçbir bakım girişimi el yıkamadan başlamamalıdır (Haraden 2015; McCarron 2011). Bir bakım paketinde değişiklik yapılması düşünüldüğünde bunun mutlaka bilimsel temellere dayandırılması gerekmektedir. Bu da ekip işbirliği gerektiren çok ciddi araştırmalarla ortaya konulmaktadır. Bu şartlarda (yüksek kanıtlara dayalı) değiştirilmiş bir bakım paketinin başarı şansı daha yüksek olmaktadır (Aboelela ve ark. 2007; Fulbrook ve Mooney 2003; Horner ve Bellamy 2012; McCarron 2011).

Üçüncü sorun, paket kavramının yanlış anlaşılması ve kullanılmasıdır. Örneğin, hasta bakım işlemlerini içeren herhangi bir kontrol listesine "paket" demek gibi. Ancak, bakım paketi bir kontrol listesi değildir. Kontrol listesine "bakım paketi" demek, süreci daha güvenilir yapmamakta ve bakım sonuçlarını iyileştirmemektedir. Burada önemli olan, iyileştirme sonuçları üzerinde paketin bilimsel ilkelere göre organize edilme şeklidir (Haraden 2015).

Haraden (2015)'e göre hekim ve hemşireler bir kontrol listesini bakım paketi yapmak istiyorlarsa, kendilerine şu soruyu sormalıdırlar: "ona bakım paketi demek, neden daha iyi yapsın?”. Hekim ve hemşireler bakım paketi, bakım protokolleri ve kontrol listesi arasındaki fark ve benzerlikleri bilirlerse onları onları etkin kullanırlar, tedavi ve bakımlarında beklenen pozitif sonuçlara ulaşabilirler.

$\mathrm{Bu}$ durumlar göz önünde bulundurulduğunda, bakım paketi uygulayacak sağlık ekibinin, paket uygulaması konusunda bilgilendirilmesinin ve bir uyum süreci izleminin yapılmasının önemli olduğu bildirilmektedir (Borgert ve Goossens 2015; Lawrence ve Fulbrook 2012). Bununla birlikte Hamishehkar ve ark. (2014) yapmış oldukları çalışmada, ventilatörle ilişkili pnömoniyi azaltmada bakım paketlerinin doğru kullanılması konusunda verilen eğitimlerin çok etkili olmadığını bildirmişlerdir. Çözümün, paketin gelişim sürecinde yer almak olabileceği ileri sürülmektedir.

\section{Bakım Paketi Geliştirilmesi}

Bir bakım paketi geliştirilmesinde en önemli nokta ona gereksinim duyulmasıdır. Paket geliştirmede izlenmesi gereken bazı adımlar vardır. Bu adımlar tablo 2'de özetlenmiştir (Fulbrook ve Mooney 2003).

Tablo 2. Bakım Paketi Geliştirmede Teorik Adımlar

\begin{tabular}{|ll|}
\hline 1. & Kritik bakım konusu/ sorunu tanımlanır \\
\hline 2. & Girişimler kümesi belirlenir, listelenir \\
\hline $\begin{array}{l}\text { 3. } \\
\text { incelenir }\end{array}$ \\
\hline 4irişimlerin her biriyle ilgili erişilebilir literatür \\
\hline 5. & Araştırmalar ayışırmalar kalitelerine göre sınıflandırılır \\
\hline 6. & $\begin{array}{l}\text { Listelenmiş girişimlerden, araştırmalar doğrultusunda } \\
\text { yeterli kanıt düzeyine sahip olmayanlar listeden çıarılır }\end{array}$ \\
\hline 7. & $\begin{array}{l}\text { Yüksek düzeyli kanıtlar üzerinden, kanıt temelli } \\
\text { girişimimler geliştirilir ve uygulanır }\end{array}$ \\
\hline
\end{tabular}

Kaynak: Fulbrook, P., Mooney, S. (2003). Care bundles in critical care: A practical approach to evidence-based practice. Nurs Crit Care, 8(6): 249-255.

Paket geliştirmeyi gerektiren bir konu/ sorun varsa, sorunun kapsamı tanımlanarak, çözümünde görev alacak bir "ekip" kurulması gerekmektedir. Ekibin içinde hemşire ve hekimlerin olmasının, geliştirilen pakete sahip çıkılmasını ve işbirliğini sağlayacağı bildirilmektedir (Hamishehkar ve ark. 2014; McCarron 2011).

Ekip tarafından mevcut sorun değerlendirilmeli (beyin firtınası yöntemi, problem havuzu yöntemi gibi), girişimlerin neler olacağına karar verilmeli, bir kanıta dayalı model analizi yapılarak iş planı (kaynak taramak, sinıflandirmak, verileri toplamak, analizleri yapmak ve değerlendirmek, sonuçları paylaşmak gibi) oluşturulmalıdır (Fulbrook ve Mooney 2003).

Soruna özgü konuyla ilgili literatür tarayarak ilk büyük adım gerçekleştirilmelidir. Literatür için randomize kontrollü deneysel çalışmalardan, bu çalışmaları içeren meta-analizlerden ve /veya sistematik eleştirel inceleme makaleleri (review) aracılığı ile oluşturulmuş klinik uygulama rehberlerinden ve uzman görüşlerinden yararlanılabilir. Büyük örneklemlerden elde 
edilmiş kanıtlara ulaşmak için Hemşirelik Kümülatif İndeksi Sağlık Literatürü (The Cumulative Index to Nursing Allied Health Literature) (CINAHL), ABD Ulusal Tip Kütüphanesi (The U.S. National Library of Medicine), The Cochrane Kütüphanesi gibi veri tabanlarına başvurulabilir. Ayrıca Birşelik Devletler kanit temelli uygulama rahberlerine de The National Guideline Clearinghouse'un web sayfasından ulaşabilir ve bunların dışında her ülke kendi veri tabanlarını da araştırabilir (Fulbrook ve Mooney 2003).

Literatür taranarak elde edilen kaynaklar incelenmeli ve bunlar kanıt düzeylerine göre sinıflandırılmalıdır. Daha sonra belirlenen hasta grubuna göre bakım paketinde yer alacak girişimler konusunda uzlaşma sağlanmalıdır (McCarron 2011).

Bakım paketi geliştirilirken, genel olarak, en önemli kurallardan biri de paket bileşenlerinin "yapılması gereken işlemleri” içermesine dikkat etmektir. Yapılmayacak işlemler (örneğin, hastayı sırtüstü yatırmayın gibi), işlem sürecinde/ paket hazırlık sürecinde bir yetersizlik olduğunu göstermektedir (McCarron 2011).

Yeni uygulamaya konulmuş bir bakım paketinin başarısında uyum önemlidir (Lawrence ve Fulbrook 2012). IHI "pakete uyumu" tüm girişimlerin yerine getirilmesi olarak tanımlamıştır (IHI 2012). Bununla birlikte uyumun her hasta için \%100 olamayacağ 1 , hastaya ait bazı özel durumların (örnek kanamalı hastada derin ven trombozu profilaksisi uygulanmaması gibi) yaşanabileceği ifade edilmektedir. Uyum sorunlar1nın, özellikle hizmeti sunanlardan kaynaklı olmaması çok önemlidir (Çetinkaya-Şardan 2010; Lawrence ve Fulbrook 2011; Lawrence ve Fulbrook 2012).

Çalışmalarda, bakım paketi uygulamaya konulduktan sonra gerçekçi hedefler ve bu hedeflere uyum düzeyinin değerlendirilmesi önerilmektedir (Çetinkaya-Şardan 2010; Lawrence ve Fulbrook 2011; Lawrence ve Fulbrook 2012). Youngguist ve ark. (2007) yaptıkları çalışmalarında ventilator bakım paketine uyum düzeyi ile enfeksiyon oranı arasındaki ilişkiyi incelemişlerdir. Pakete uyum düzeyi arttıkça buna paralel olarak enfeksiyon oranının da düştüğü sonucuna ulaşmışlardır.
Uyum değerlendirmelerinin genellikle haftalık, aylık, ilk altı aylık, ikinci altı aylık ve yıllık şeklinde yapılması önerilmektedir. Bu sürelere göre beklenen bir uyum düzeyi olmalıdır. Beklenen uyum düzeyinin $\% 95$ ve üzeri olması için bir yıl ve daha uzun süre gerektiği gösterilmiştir. Multidisipliner ekip toplantıları yapılarak paylaşımda bulunulmasının uyumu artırdı ğ bildirilmiştir (Lawrence ve Fulbrook 2012).

\section{SONUÇ VE ÖNERILLER}

Bakım paketi; bakım göstergelerinin, en iyi kanıtlarla net bir şekilde açıklanmış olduğu bir araçtır. Hasta için, yaşamsal önem taşıyan, yeterli ve zorunlu bakım girişimlerini gösterir. Girişimlerin sayısı sınırlıdır (genellikle 3-5). Her hasta için aynı ölçütlerin karşılaması gerektiğini gösterir. Kanıt temelli yapısı dinamik bir süreçtir, yeni kanıtlar doğdukça değişir. Mümkün olan en iyi bakımı sağlamak ve olumlu/ yararlı sonuçlar elde etmek için belli bir ekip tarafından ve bütün olarak uygulanmayı gerektirir. İçerdiği girişimlerin bütün olarak yapılmaması beklenen başarıya ulaşılmasını engelleyen en önemli nedendir. Ayrica, paket maddelerinin yüksek düzeyli kanıtlara dayandırılmadan değiştirilmesi ya da bu maddelere ilaveler yapılması da paketin gücünü zayıflatan girişimler arasındadır. $\mathrm{Bu}$ tip girişimler, aslında güçlü olan paket uygulamasının inandırıcılığına gölge düşürülmesine yol açmaktadır. Bu durum genellikle bilgisizlik ya da paket ile çalışmaya yeterince uyum sağlanamadığında ortaya çıkmaktadır. Tüm girişimler için beklenen uyum düzeyinin, hasta adına pozitif bir karar almayı gerektiren bir durum dışında, \%100 olması beklenmektedir. Kritik bakım alanlarında morbidite ve mortalitenin azaltılmasında doğru anlaşılması ve doğru kullanılması, oldukça önemlidir.

\section{KAYNAKLAR}

Aboelela, S. W., Stone, P. W, Larson, E. L. (2007). Effectiveness of bundled behavioural interventions to control health care associated infections: A systematic review of the literature. J Hosp Infect., 66(2): 101-108.

Berenholtz, S. M., ve ark. (2004). Improving care for the ventilated patient. Jt Comm J Qual Saf., 30(4): 195-204. 
Berenholtz, S., Dorman, T., Ngo, K., Provonost, P. J. (2002). Qualitative review of intensive care quality indicators. $J$ Crit Care, 17(1): 1-12.

Borgert, M. J., Goossens, A., Dongelmans, D. A. (2015). What are effective strategies for the implementation of care bundles on ICUs: A systematic review. Implement Sci., 10: 119.

Clark, K., Curry, T., Byfieldt, N. (2015). The effect of a care bundle on nursing staff when caring for the dying. Int J Palliat Nurs., 21(8): 392-398.

Cooke, F. J., Holmes, A. H. (2007). The missing care bundle: Antibiotic prescribing in hospitals. Int Journal Antimicrob Agents, 30(1): 25-29.

Coyer, F., ve ark. (2015). Reducing pressure injuries in critically ill patients by using a patient skin integrity care bundle (inSPIRE). $\mathrm{Am}$ J Crit Care, 24(3): 199-210.

Çetinkaya-Şardan, Y. (2010). İnfeksiyon kontrolünde paketler. Yoğun Bakım Dergisi, 9(4): 188-192.

Fong, J. J. ve ark. (2007). Factors influencing variability in compliance rates and clinical outcomes among three different severe sepsis bundles. Ann Pharmacother, 41(6): 929-936.

Fulbrook, P., Mooney, S. (2003). Care bundles in critical care: A practical approach to evidence-based practice. Nurs Crit Care, 8(6): 249-255.

Hamishehkar, H., ve ark. (2014). Education alone is not enough in ventilator associated pneumonia care bundle compliance. $J$ Res Pharm Pract., 3(2): 51-55.

Haraden, C. (2015). What is a bundle? (Cited 2015 September 11), http://www.ihi.org/resources/Pages/ImprovementStories/WhatIsaBundle.aspx. (08.10.2015).

Horner, D. L., Bellamy, M. C. (2012). Care bundles in intensive care. Continuing Education in Anaesthesia, Critical Care \& Pain, $\mathrm{http} / / /$ ceaccp.oxfordjournals.org (12.11.2015).
Institute for Healthcare Improvement (IHI) (2012). How-to guide: Prevent ventilator-associated pneumonia. Cambridge, MA: Institute for Healthcare Improvement 2012, http://www.chpso.org/sites/ main/files/file-attachments/ihi_howtoguidepreventvap.pdf (29.12. 2015).

Lashoher, A., Pronovost, P. (2010). Creating a more efficient healthcare knowledge market: Using communities of practice to create checklists. Qual Saf Health Care, 19(6): 471-472.

Lawrence, P., Fulbrook, P. (2012). Effect of feedback on ventilator care bundle compliance: Before and after study. Nurs Crit Care, 17(6): 293-301.

Lawrence, P., Fulbrook, P. (2011). The ventilator care bundle and its impact on ventilator-associated pneumonia: A review of the evidence. Nurs Crit Care, 16(5): 222-234.

Malouf-Todaro, N., Barker, J., Jupiter, D., Tipton, P. H., Peace, J. (2013). Impact of enhanced ventilator care bundle checklist on nursing documentation in an intensive care unit. J Nurs Care Qual., 28(3): 233-240.

Marwick, C., Davey, P. (2009). Care bundles: The holy grail of infectious risk management in hospital? Curr Opin Infect Dis., 22(4): 364-369.

McCarron, K. (2011). Understanding care bundles. Lippincott Williams \& Wilkins, (Cited 2015 September 27), http://www.NursingMadeIncrediblyEasy.com. (12.10.2015).

Smith, M. (2007). A care bundle for management of central venous catheters. Paediatr Nurs., 19(4): 39-44.

Vijayasekar, C., Steele, R. J. C. (2009). The World Health Organization's surgical checklist. Surgeon, 7(5): 260-262.

Youngquist, P. ve ark. (2007). Implementing a ventilator bundle in a community hospital. Jt Comm J Qual Patient Saf., 33(4): 219224. 